\title{
Purification and Properties of a Lectin in the Skin Mucus of the Dragonet Repomucenus richardsonii
}

\author{
Kazuo Shiomi,* Hideo Uematsu, * Hiroshi Ito,* \\ Hideaki Yamanaka, ${ }^{*}$ and Takeaki Kikuchi*
}

(Received August 23, 1989)

\begin{abstract}
A lectin in the skin muscus of the dragonet Repomucenus richardsonii was purified to an electrophoretically pure state by affinity chromatography on Sepharose $4 B$ and HPLC on Chemcosorb 300-7CM. The purified lectin was an acidic glycoprotein with an isoelectric point of 6.1. Its molecular weigh was determined to be 48000 by HPLC on TSK-gel G3000SW or 12000 by SDS electrophoresis, suggesting that it exists as a tetramer of the same subunit. The amino acid composition was characterized by the abundance of glycine, acidic amino acids and hydroxy amino acids and the absence of sulfur-containing amino acids. Inhibition tests revealed that the purified lectin has high affinity for D-galactose related sugars, especially lactose, and two glycoproteins (asialofetuin and mucin).
\end{abstract}

Lectins, sugar-binding proteins or glycoproteins, have so far been found in various biological sources, mainly terrestrial plants. Because of their unique biological activities such as cell agglutination and mitogenic activitity, they are frequently utilized as pharmacological reagents. The fish skin mucus also seems to be a rich source of lectins; lectins have been detected in the skin mucus of the catfish Tachysurus australinus, ${ }^{1)}$ the Pacific hagfish Eptatretus stoutii, ${ }^{2)}$ the windowpane flounder Lophopsetta maculata, ${ }^{3)}$ the member of Ophidiidae Genypterus blacodes, ${ }^{4)}$ the Japanese eel Anguilla japonica, ${ }^{\mathrm{b})}$ and the Arabian Gulf catfish Arius thalassinus. ${ }^{\text {) }}$

Recently, a wide distribution of lectins in the fish skin mucus was confirmed by our survey, in which 23 of 33 fish were shown to contain lectins in their skin mucus. ${ }^{72}$ Furthermore, a galactosebinding lectin in the skin mucus of the conger eel Conger myriaster has already been purified and characterized. ${ }^{8)}$ Independently, properties of the conger eel lectin were also reported by Kamiya et al. ${ }^{\text {e) }}$ In this communication we describe the purification and properties of a lectin in the skin mucus of another positive species, the dragonet Repomucenus richardsonii.

\section{Materials and Methods}

\section{Fish}

Specimens of $R$. richardsonii were collected in shallow waters of Lake Hamana and immediately frozen. They were transported frozen to our laboratory and stored at $-20^{\circ} \mathrm{C}$ until use.

\section{Extraction}

The skin mucus was collected from half-thawed specimens by scraping with a spatula, and homogenized in 5 volumes of $0.01 \mathrm{M}$ phosphate buffer (pH 6.0). The homogenate was centrifuged at $15000 \mathrm{rpm}$ for $20 \mathrm{~min}$ and the supernatant obtained was used as crude extract.

\section{Purification Procedure}

The crude extract was applied to a Sepharose 4B column (Pharmacia Chem. Co., $2 \times 55 \mathrm{~cm}$ ) equilibrated with $0.01 \mathrm{M}$ phosphate buffer $(\mathrm{pH} 6.0)$. The column was first eluted with the same buffer until the absorbance at $280 \mathrm{~nm}$ of the eluate was back to the background level, and then with $0.1 \mathrm{M}$ lactose in the buffer. Fractions of $4 \mathrm{ml}$ were collected at a flow rate of $15 \mathrm{~m} / / \mathrm{h}$. Active fractions were combined and subjected to high performance liquid chromatography (HPLC) on a Chemcosorb 300-7CM column (Chemco Sci. Co., $0.46 \times 25 \mathrm{~cm}$ ) equilibrated with $0.01 \mathrm{M}$ phosphate buffer ( $\mathrm{pH} \mathrm{6.0)}$ ). After washing with the buffer, the column was eluted by a linear gradient of $\mathrm{NaCl}(0.0-1.0 \mathrm{M})$ in the buffer, which was terminated in $15 \mathrm{~min}$. The flow rate was maintained at $1 \mathrm{~m} l / \mathrm{min}$. Lectin-containing fractions were manually collected, dialyzed against distilled water and

* Department of Food Science and Technology, Tokyo University of Fisheries, Konan, Minato, Tokyo 108, Japan（塩見一雄, 植松英夫, 伊藤 洋, 山中英明, 蔽池武昭: 東京水産大学食品生産学科). 
lyophilized.

\section{Assay of Hemagglutinating Activity}

Only rabbit erythrocytes were used for assay of hemagglutinating activity since they were most sensitive to the crude extract. ${ }^{\text {7) }}$ Hemagglutinating activity was determined by the method of Shiomi et al. ${ }^{10)}$ and expressed in terms of minimum active concentration ( $\mu \mathrm{g}$ protein $/ \mathrm{ml}$ ) required for positive agglutination or in terms of titer value, the reciprocal of the highest dilution of sample giving positive agglutination.

\section{Inhibition Assay by Sugars and Glycoproteins}

Inhibition tests were performed according to the method of Shiomi et al. ${ }^{10)}$ A mixture of sample (titer 4) and sugar was assayed for hemagglutinating activity after being kept at $4^{\circ} \mathrm{C}$ for $1 \mathrm{~h}$. The following sugars were used: D-galactose, D-galactosamine, N-acetyl-D-galactosamine, lactose, melibiose, raffinose, stachyose, D-glucose, D-glucosamine, N-acetyl-D-glucosamine, D-glucuronic acid, maltose, cellobiose, sucrose, D-arabinose, Larabinose, D-fructose, D-fucose, L-fucose, Dmannose, inositol and sorbitol. N-Acetyl-D-galactosamine, D-fucose and D-glucuronic acid were purchased from Aldrich Chem. Co., and the other sugars from Wako Pure Chem. Ind. The following glycoproteins were also used: fetuin (type III, from fetal calf serum), asialofetuin (type I, from fetal calf serum), mucin (type I, from bovine submaxillary glands), orosomucoid ( $\alpha_{1}$-acid glycoprotein, from human cohn fraction VI), ovalbumin (gel filtration calibration kit) and ovomucoid (trypsin inhibitor, type III-0, from chicken egg white). All glycoproteins were obtained from the Sigma Chem. Co., except ovalbumin from the Pharmacia Chem. Co.

\section{Protein Determination}

Protein was determined by the method of Lowry et al., ${ }^{11}$ using bovine serum albumin as a standard.

\section{Analytical Electrophoresis}

Analytical disc electrophoresis was performed as described by Davis ${ }^{12)}$ using a $7 \%$ polyarylamide gel and Tris-glycine buffer ( $\mathrm{pH} 8.3$ ). After running, the gei was stained for proteins with Coomassie Brilliant Blue R-250 or for sugars with periodic acid-Schiff (PAS) reagent according to the method of Zacharius et al. ${ }^{13)}$

\section{Molecular Weight Determination}

The molecular weight of the purified lectin was determined either by gel filtration or by sodium dodecyl sulfate (SDS) disc electrophoresis. Gel filtration was carried out by HPLC on a TSK-gel G3000SW column (Tosoh Co., $0.75 \times 30 \mathrm{~cm}$ ) with $0.2 \mathrm{M}$ phosphate buffer (pH 6.8). The fiow rate was maintained at $1 \mathrm{~m} / / \mathrm{min}$ and the eluate monitored by absorbance at $280 \mathrm{~nm}$. Bovine serum albumin (MW 67000), ovalbumin (MW 43000), ribonuclease A (MW 13700) and cytochrome c (MW 12500) were used to calibrate the column. SDS disc electrophoresis was performed as described by Weber and Osborn ${ }^{14}$ using a $10 \%$ polyacrylamide gel and $0.1 \mathrm{M}$ phosphate buffer (pH 7.2) containing $0.1 \%$ SDS. After running, the gel was stained with Coomassie Brilliant Blue R-250. The reference proteins used were bovine serum albumin, ovalbumin, chymotrypsinogen A (MW 25000) and ribonuclease A.

\section{Electrofocusing}

Electrofocusing on a $7.5 \%$ polyacrylamide gel was carried out as described in our previous paper $^{8)}$ Colored pI marker proteins (Oriental Yeast $\mathrm{Co}$.) were used to know the $\mathrm{pH}$ gradient formed.

\section{Amino Acid Analysis}

The purified lectin $(100 \mu \mathrm{g})$ was hydrolyzed with $50 \mu \mathrm{l}$ of $4 \mathrm{~N}$ methanesulfonic acid containing $0.2 \%$ 3-(2-aminoethyl)indole in an evacuated tube at $110^{\circ} \mathrm{C}$ for $24 \mathrm{~h}$. After neutralization with $3.5 \mathrm{~N}$ $\mathrm{NaOH}$, the hydrolysate was applied to a Hitachi 835 amino acid analyzer.

\section{Results and Discussion}

\section{Purification}

Fig. 1 shows the elution profile of the crude extract from a Sepharose $4 \mathrm{~B}$ column. Although almost all proteins contained in the crude extract were eluted with $0.01 \mathrm{M}$ phosphate buffer $(\mathrm{pH}$ 6.0 ), no hemagglutinating activity was detected in the buffer eluate. Further elution with $0.1 \mathrm{M}$ lactose in the buffer afforded a small protein peak with hemagglutinating activity, suggesting that the $R$. richardsonii lectin specifically binds to Sepharose 4B. When the active fraction was then subjected to HPLC on Chemcosorb 300-7CM, the lectin was separated from inactive proteins and eluted in a symmetrical protein peak (Fig. 2). The final preparation thus obtained was homogeneous as judged by analytical disc electrophoresis (Fig. 3). The purified lectin was designated as richardsonin. In a typical run, $0.5 \mathrm{mg}$ of rich- 


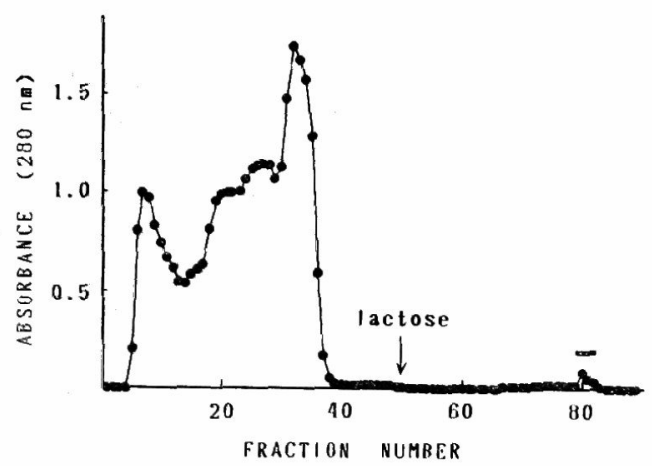

Fig. 1. Affinity chromatography of the R. richardsonii lectin.

The crude extract was applied to a Sepharose 4B column $(2 \times 55 \mathrm{~cm})$ equilibrated with $0.01 \mathrm{M}$ phosphate buffer ( $\mathrm{pH}$ 6.0). After washing with the buffer, the column was eluted with $0.1 \mathrm{M}$ lactose in the buffer (indicated by an arrow). Fractions of $4 \mathrm{~m} /$ were collected at a flow rate of $15 \mathrm{~m} / / \mathrm{h}$. A bar represents the lectin fraction.

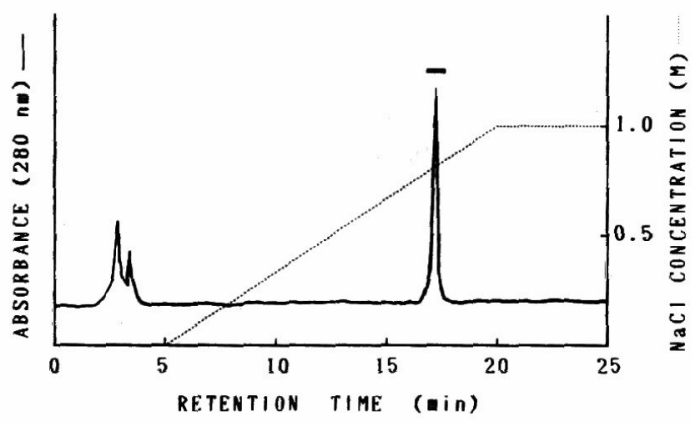

Fig. 2. HPLC of the $R$. richardsonii lectin.

The lectin fraction obtained by affinity chromatography (Fig. 1) was subjected to HPLC using a Chemcosorb 300-7CM column $(0.46 \times$ $25 \mathrm{~cm}$ ) equilibrated with $0.01 \mathrm{M}$ phosphate buffer (pH 6.0). After washing with the same buffer, the column was eluted at a flow rate of $1 \mathrm{~m} / / \mathrm{min}$ by a linear gradient of $0-1.0 \mathrm{M} \mathrm{NaCl}$ in the buffer. A bar represents the lectin fraction.

ardsonin was obtained from the skin mucus of 16 specimens. The minimum agglutinating concentration of richardsonin against rabbit erythrocytes was estimated to be $0.14 \mu \mathrm{g} / \mathrm{m} l$.

Affinity chromatography on Sepharose 4B was very effective in purfying richardsonin. Previously epoxy-activated Sepharose 4B, to which Dgalactose was coupled, was used as an adsorbent for the purification of the conger eel lectin. ${ }^{8)}$ As described below, richardsonin, like the conger eel lectin, binds to D-galactose related sugars. However, purification of richardsonin by affinity

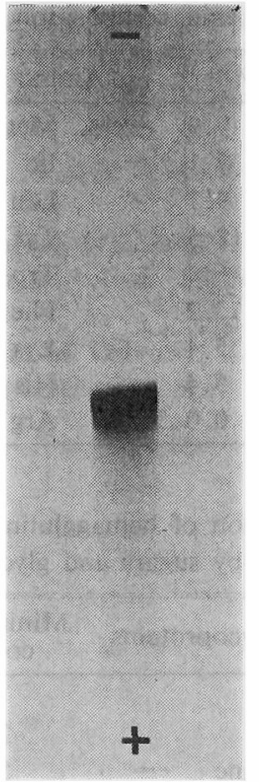

Fig. 3. Analytical disc electrophoresis of the purified lectin.

After running on a $7 \%$ polyacrylamide gel with Tris-glycine buffer ( $\mathrm{pH} \mathrm{8.3),} \mathrm{the} \mathrm{lectin} \mathrm{was}$ visualized with Coomassie Brilliant Blue R-250.

chromatography on epoxy-activated Sepharose 4B, to which D-galactose or lactose was coupled, was unsuccessful. When the crude extract was applied to an epoxy-activated Sepharose 4B column, richardsonin was nearly passed through the column due to the non-specific binding of a large amounts of inactive proteins to the column.

\section{Physicochemical Properties}

Richardsonin was heat labile; its hemagglutinating activity was reduced to one-half by heating at $60^{\circ} \mathrm{C}$ for $10 \mathrm{~min}$ and completely lost by heating at $70^{\circ} \mathrm{C}$ for $10 \mathrm{~min}$. Since the activity was neither reduced nor enhanced both upon dialysis against $50 \mathrm{~mm}$ EDTA and in the presence of $10 \mathrm{~mm}$ divalent cations $\left(\mathrm{Ba}^{2+}, \mathrm{Ca}^{2+}, \mathrm{Co}^{2+}, \mathrm{Mg}^{2+}\right.$, and $\mathrm{Mn}^{2+}$ ), the lectin appeared to be independent of divalent cations for its activity.

Richardsonin was positive to PAS staining, suggesting that it is a glycoprotein, like the ophidiid fish lectin ${ }^{4)}$ but unlike the windowpane flounder ${ }^{3)}$ and conger eel ${ }^{8, \theta)}$ lectins. It gave only one symmetrical peak in HPLC on TSK-gel G3000SW and gave a single band in SDS disc electrophoresis, supporting again its homogeneity. The molecular weight was determined to be 48000 by HPLC and 12000 by SDS electrophoresis, which indicated that richardsonin exists as a tetramer of the same 
Table 1. Amino acid composition of richardsonin

\begin{tabular}{crcc}
\hline Amino acid & Mol \% & Amino acid & Mol \% \\
\hline Asp & 9.9 & Met & 0.0 \\
Thr & 7.1 & Ile & 5.6 \\
Ser & 9.7 & Leu & 5.5 \\
Glu & 12.5 & Tyr & 5.4 \\
Pro & 5.4 & Trp & 0.5 \\
Gly & 13.2 & Phe & 3.9 \\
Ala & 5.4 & Lys & 5.4 \\
Val & 5.4 & His & 2.5 \\
Cys & 0.0 & Arg & 2.8 \\
\hline
\end{tabular}

Table 2. Inhibition of hemagglutinating activity of richardsonin by sugars and glycoproteins

\begin{tabular}{lc} 
Sugars and glycoproteins & $\begin{array}{c}\text { Minimum inhibitory } \\
\text { concentration* }\end{array}$ \\
\hline Sugars & $25(\mathrm{~mm})$ \\
D-Galactose & 50 \\
D-Galactosamine & 100 \\
N-Acetyl-D-galactosamine & 2.5 \\
Lactose & 25 \\
Melibiose & 25 \\
Raffinose & 10 \\
Stachyose & $>1$ (mg/ml) \\
Glycoproteins & 0.1 \\
Fetuin & 0.75 \\
Asialofetuin & $>1$ \\
Mucin & $>1$ \\
Orosomucoid & $>1$ \\
Ovalbumin & \\
Ovomucoid & \\
\hline The minimum inhibitory concentration is that required to \\
inhibit completely the agglutinating activity (titer 4) against \\
rabbit erythrocytes. The sugars showing no inhibition at \\
100 mM are not listed.
\end{tabular}

subunit with a molecular weight of 12000 . Such a subunit structure is known for the windowpane flounder,$^{3)}$ ophidiid fish ${ }^{4)}$ and conger ee ${ }^{8,9)}$ lectins. The isoelectric point of richardsonin was estimated to be 6.1 by electrofocusing. Differing from the windowpane flounder ${ }^{3)}$ and conger ee ${ }^{(,, 9)}$ lectins, richardsonin afforded a single band in electrofocusing, suggesting the absence of isolectins. The amino acid composition is summarized in Table 1. It was characterized by the abundance of acidic amino acids (aspartic acid and glutamic acid), hydroxy amino acids (threonine and serine) and glycine but the absence of sulfur-containing amino acids (half-cystine and methionine). The absence of half-cystine implies that the disulfide bonding is not involved in the association of subunits.

\section{Sugar Inhibition}

As shown in Table 2, the hemagglutinating activity of richardsonin was inhibited by $D$ galactose, its derivatives (D-galactosamine and $\mathrm{N}$-acetyl-D-galactosamine) and its containing sugars (lactose, melibiose, raffinose and stachyose); lactose was the most potent inhibitor. These results are consistent with those obtained with the crude extract. ${ }^{7)}$ Although none of the glycoproteins tested showed any inhibitory effect on the crude extract,? the purified lectin was inhibited by two glycoproteins, asialofetuin and mucin.

In our previous paper, ${ }^{7}$ the lectins in the skin mucus of eight fish species were tested for their sugar specificity. As a result, as many as seven lectins were found to bind to D-galactose and its related sugars. The Arabian Gulf catfish lectin was also reported to be inhibited by D-galactose related sugars. ${ }^{\theta)} \quad$ Therefore, it is likely that many lectins in the fish skin mucus are highly specific for D-galactose related sugars. Richardsonin is obviously one of those lectins. However, there is a distinct difference in sugar specificity among these D-galactose binding lectins. For example, richardsonin is specific for all of the D-galactose related sugars tested, while the Arabian Gulf catfish lectin is not inhibited by raffinose and stachyose even at a concentration of $100 \mathrm{~mm}^{\left.{ }^{6}\right)}$ Moreover, the conger eel lectin is also inhibited by sugars (D-, L-arabinose and D-mannose) other than Dgalactose related sugars. ${ }^{\text {B) }}$ Further study is needed to elucidate the sugar structure recognized by each lectin.

\section{Acknowledgements}

We are grateful to Dr. Y. Suzuki, the University of Tokyo, for collecting dragonet specimens and to Professor S. Konosu and Dr. A. Shinagawa, the University of Tokyo, for measuring the amino acid composition of the purified lectin.

\section{References}

1) J. J. Di Conza: Aust. J. Exp. Biol. Med. Sci., 48, 515-523 (1970).

2) R. H. Spitzer, S. W. Downing, and M. A. Kaplan: Comp. Biochem. Physiol, 54B, 409-411 (1976).

3) H. Kamiya and Y. Shimizu: Biochim. Biophys. Acta, 622, 171-178 (1980).

4) Y. Oda, S. Ichida, T. Mimura, K. Maeda, K. Tsujikawa, and S. Aonuma: J. Pharm. Dyn., 7, 614-623 (1984).

5) Y. Suzuki: Nippon Suisan Gakkaishi, 51, 2083 (1985). 
6) J. M. Al-Hassan, M. Thomson, B. Summers, and R. S. Criddle: Comp. Biochem. Physiol., 85B, 31-39 (1986).

7) K. Shiomi, H. Uematsu, H. Yamanaka, and T. Kikuchi: J. Tokyo Univ. Fish., 75, 145-152 (1988).

8) K. Shiomi, H. Uematsu, H. Yamanaka, and T. Kikuchi: Comp. Biochem. Physiol., 92B, 255263 (1989).

9) H. Kamiya, K. Muramoto, and R. Goto: $D e v$. Comp. Immunol., 12, 309-318 (1988).

10) K. Shiomi, H. Kamiya, and Y. Shimizu: Biochim.
Biophys. Acta, 576, 118-127 (1979).

11) O. H. Lowry, N. J. Rosebrough, A. L. Farr, and R. J. Randall: J. Biol, Chem., 193, 265-275 (1951).

12) B. J. Davis: Ann. N. Y. Acad. Sci, 121, 404-410 (1964).

13) R. M. Zacharius, T. E. Zell, T. H. Morrison, and J. J. Woodlock: Anal. Biochem, 30, 148-152 (1969).

14) K. Weber and M. Osborn: J. Biol. Chem., 244, $4406-4412$ (1969). 